DR ALDO DOMINGO MOTTINO (Orcid ID : 0000-0002-4142-0410)

Article type : Regular Paper

\title{
Intraluminal nutrients acutely strengthen rat intestinal MRP2 barrier function by a glucagon-like peptide-2-mediated mechanism
}

\author{
Guillermo Nicolás Tocchettia,b \\ Camila Juliana Domíngueza \\ Felipe Zecchinatia \\ Maite Rocío Aranaa \\ Juan Pablo Rigallib \\ María Laura Ruiza \\ Silvina Stella Maris Villanuevaa \\ Aldo Domingo Mottino ${ }^{\mathrm{a},{ }^{*}}$
}

alnstitute of Experimental Physiology (IFISE); National Scientific and Technical Research Council (CONICET) - National University of Rosario (UNR); Suipacha 570, S2002LRL Rosario, Argentina.

This article has been accepted for publication and undergone full peer review but has not been through the copyediting, typesetting, pagination and proofreading process, which may lead to differences between this version and the Version of Record. Please cite this article as doi: 10.1111/APHA.13514

This article is protected by copyright. All rights reserved 
bDepartment of Clinical Pharmacology and Pharmacoepidemiology; University of Heidelberg; Im Neuenheimer Feld 410, 69120 Heidelberg, Germany.

*Correspondence: amottino@unr.edu.ar

Short title: Nutrients and intestinal MRP2 barrier 


\section{Abstract}

Aim: MRP2 is an intestinal ABC transporter that prevents the absorption of dietary xenobiotics. The aims of this work were: i) to evaluate whether a short-term regulation of intestinal MRP2 barrier function takes place in vivo after luminal incorporation of nutrients and ii) to explore the underlying mechanism.

Methods: MRP2 activity and localization were assessed in an in vivo rat model with preserved irrigation and innervation. Nutrients were administered into distal jejunum. After 30-min treatments, MRP2 activity was assessed in proximal jejunum by quantifying the transport of the model substrate 2,4-dinitrophenyl-S-glutathione. MRP2 localization was determined by quantitative confocal microscopy. Participation of extracellular mediators was evaluated using selective inhibitors and by immunoneutralization. Intracellular pathways were explored in differentiated Caco-2 cells.

Results: Oleic acid, administered intraluminally at dietary levels, acutely stimulated MRP2 insertion into brush border membrane. This was associated with increased efflux activity and, consequently, enhanced barrier function. Immunoneutralization of the gut hormone glucagon-like peptide-2 (GLP-2) prevented oleic acid effect on MRP2, demonstrating the participation of this trophic factor as a main mediator. Further experiments using selective inhibitors demonstrated that extracellular adenosine synthesis and its subsequent binding to enterocytic A2B adenosine receptor (A2BAR) take place downstream GLP-2. Finally, studies in intestinal Caco-2 cells revealed the participation of A2BAR/cAMP/PKA intracellular pathway, ultimately leading to increased MRP2 localization in apical domains.

Conclusion: These findings reveal an on-demand, acute regulation of MRP2-associated barrier function, constituting a novel physiological mechanism of protection against the absorption of dietary xenobiotics in response to food intake. 


\section{Keywords}

MRP2, adenosine, GLP-2, intestinal barrier, intestine, oleic acid 


\section{Introduction}

The small intestine constitutes a biochemical barrier between external and internal environments which depends on the proper localization and activity of ATP-binding cassette $(A B C)$ transporters. $A B C$ efflux pumps, particularly localized to the brush border membrane (BBM) of the enterocyte, are responsible for actively extruding xenobiotics back to the intestinal lumen. Among these transporters, the multidrug resistanceassociated protein 2 (MRP2; also known as ABCC2) has a wide substrate specificity, limiting the absorption of numerous prescription drugs and food contaminants. ${ }^{1,2}$ Intestinal MRP2 expression and localization were first described two decades ago. Enterocytes from the tip of the villus exhibited the maximal MRP2 expression with a decreasing pattern towards the cells from the crypt. A gradient along the intestinal tract was also found, with the highest MRP2 content in proximal jejunum decreasing towards the ileum. ${ }^{3,4}$ Although these studies have been performed in rats, a similar distribution was subsequently demonstrated in humans. ${ }^{5,6}$ MRP2 relevance as a key component of the intestinal barrier was demonstrated using TR- rats, in which this transporter is hereditarily defective. As result of oral bioavailability studies, TR- rats showed increased absorption, plasma concentration and tissue accumulation of the dietary carcinogen 2amino-1-methyl-6-phenylimidazo[4,5-b]pyridine (PhIP) when compared to normal Wistar rats. ${ }^{7}$

Glucagon-like peptide-2 (GLP-2) is a 33 amino acid peptide produced by enteroendocrine $\mathrm{L}$ cells from distal jejunum, ileum and colon epithelia. Its vast repertoire of actions at the intestinal level includes both long-term and short-term effects focused on improving intestinal functions such as digestion and absorption. Among long-term effects are the increase in proliferation and the decrease in apoptosis of epithelial cells, eventually leading to intestinal hypertrophy and hyperplasia. ${ }^{8-10}$ Among short-term effects, the most remarkable is the increase in intestinal blood flow after meals, also known as postprandial hyperemia. ${ }^{11,12}$ GLP-2 exerts these biological functions by binding to GLP2R, a G protein-coupled receptor expressed in enteric neurons, subepithelial myofibroblasts and enteroendocrine cells of the intestine. ${ }^{13}$ Interestingly, the presence of

GLP-2R was ruled out both in epithelial crypt cells and in differentiated enterocytes, i.e. the main targets of GLP-2 actions. In fact, the multiple actions of GLP-2 at the intestinal 
level are exerted indirectly, through paracrine mediators produced by GLP-2R-expressing cells. While the polypeptide insulin-like growth factor-1 (IGF-1) was responsible for GLP-2 intestinotrophic actions, ${ }^{14,15}$ the mediators behind GLP-2 acute effects are less known. However, indirect evidence suggests that enteric neurons and extracellularly generated adenosine could play a role in this regard. ${ }^{16,17}$

The main stimulus for GLP-2 release under physiological conditions is the presence of nutrients in the digestive tract. After food intake there is a biphasic increase in circulating levels of GLP-2. The first peak occurs within the first 15-30 min, when nutrients reach the duodenum. It is triggered by an indirect mechanism involving endocrine factors and the vagus nerve, ultimately resulting in muscarinic receptor-dependent $L$ cell activation. ${ }^{18}$ The second peak occurs approximately 60-90 min after intake and involves direct luminal stimulation of $L$ cells by nutrients. Interestingly, this second peak of GLP-2 secretion depends on the specific composition of the diet, with lipids and carbohydrates being more potent stimulators than proteins..$^{19,20}$

Our group provided the first experimental evidence supporting the regulatory role of GLP2 on MRP2 function through transcriptional mechanisms. ${ }^{21}$ Additionally, subcutaneous administration of GLP-2 produced a significant increase in CAMP levels evaluated in rat enterocytes after $2 \mathrm{~h}$ of treatment. Moreover, a selective adenylate cyclase inhibitor prevented such increase, demonstrating activation of this enzymatic effector. ${ }^{21}$

Recently, we have reported that intestinal MRP2 localization may be subjected to a dynamic equilibrium between BBM and intracellular domains, thus allowing for rapid regulation of MRP2 function. ${ }^{22}$ This acute and bidirectional translocation was demonstrated for both rat and human orthologues using dibutyryl cAMP and estradiol$17 \beta$-D-glucuronide. Particularly, we described the ability of CAMP to stimulate the insertion of MRP2 into the BBM. This effect was mediated by PKA and associated with increased secretory activity of the model substrate 2,4-dinitrophenyl-S-glutathione (DNP$\mathrm{SG})$. In spite of all this evidence, it is unknown whether intestinal MRP2 acute regulation takes place in vivo as part of a physiological process.

The three main experimental findings described above can be summarized and sequentially linked as follows: (I) after intake of certain nutrients (such as oleic acid or glucose) GLP-2 is released from L cells;23 (ii) GLP-2 triggers an increase in cAMP levels of rat enterocytes; ${ }^{21}$ (iii) the increase in intracellular cAMP levels stimulates insertion of 
MRP2 into BBM with consequent impact on MRP2 transport activity. ${ }^{22}$ This sequence of events, although possible, needs experimental demonstration and constitutes our current working hypothesis. We here developed an appropriate in vivo model and demonstrated the occurrence of such events under physiological conditions. Moreover, we identified participation of additional and relevant extracellular mediators. These findings reveal a novel on-demand regulation of MRP2-associated barrier function, constituting an adaptative mechanism of protection against the absorption of dietary xenobiotics. 


\section{Results}

2.1. In vivo studies: Effect of nutrients on MRP2 activity and localization and elucidation of the extracellular mechanism involved.

2.1.1. The in vivo model provides a useful tool to detect rapid changes in MRP2 activity.

First, we established whether the proinsertor agent dbcAMP acutely increases MRP2 transport activity in our in vivo model when administered intravenously. As shown in Figure 1a, dbcAMP (20 $\mu \mathrm{mol} / \mathrm{kg}$ b.w., $20 \mathrm{~min})$ produced a significant increase $(+213 \%$ versus control) in DNP-SG efflux, demonstrating that this model allows for detection of rapid changes in MRP2 activity, at least in response to a systemic treatment.

\subsubsection{Oleic acid acutely increases MRP2 activity.}

We next evaluated the acute effect of GLP-2 releasing agents on MRP2 activity. Figure $1 \mathrm{~b}$ shows that, among the agents evaluated, only oleic acid and glucose were able to significantly modulate DNP-SG efflux in the proximal jejunum, suggesting a nutrientspecific effect. Specifically, oleic acid, administered as an emulsion at a concentration of physiological relevance, ${ }^{24}$ increased MRP2 activity in comparison with its respective control group (+231\%). Intraluminal administration of saline + Tween 20 produced no effect on MRP2 activity when compared with saline alone (data not shown), ruling out any effect of the surfactant itself. In the case of glucose, an increase was observed at the 100 $\mathrm{mM}(+186 \%)$ but not at the $10 \mathrm{mM}$ concentration, suggesting a dose-dependent effect. The effect of glutamine did not differ from that of the vehicle administered to control rats. Considering that intraluminal glucose concentrations of $100 \mathrm{mM}$ are unlikely reached after a regular meal, ${ }^{25}$ we chose oleic acid as a prototype MRP2 modulating agent for the following studies aimed at elucidating the mechanism involved.

\subsubsection{GLP-2 mediates oleic acid effect on MRP2 activity}

The next step in testing our hypothesis was to evaluate the ability of GLP-2 to acutely regulate MRP2 activity. Figure 1c shows that intravenous administration of recombinant GLP-2 (125 $\mu \mathrm{g} / \mathrm{kg}$ b.w.) significantly increases MRP2 activity (+210\%), evaluated after 20 min of treatment. Next, we assessed whether this hormone mediates oleic acid effects 
on MRP2 activity. Using a previously established GLP-2 immunoneutralization strategy, we found that the effect of oleic acid was suppressed in the oleic acid + anti-GLP-2 group (Figure 1c), confirming GLP-2 participation. Pre-administration of anti-GLP-2 did not affect MRP2 activity in rats receiving oleic acid vehicle (data not shown), ruling out any effect of immunoneutralization procedure per se.

\subsubsection{Extracellular adenosine synthesis takes place downstream GLP-2 and leads to increased MRP2 activity}

After demonstrating GLP-2 role, we evaluated the participation of IGF-1 and adenosine as mediators of GLP-2 action. In the case of IGF-1, the experimental approach consisted of IGF-1 immunoneutralization. In the case of adenosine, it consisted of selective inhibition of the adenosine receptor A2BAR and inhibition of CD73, which is considered the most important enzyme in the generation of extracellular adenosine at the intestinal level. ${ }^{26,27}$ As shown in Figure 1d, the effect of oleic acid was not prevented by anti-IGF-1 administration. In contrast, pre-treatment with MRS 1754 suppressed oleic acid effect on MRP2, confirming A2BAR participation. Moreover, APCP prevented the increase in MRP2 activity produced by both oleic acid and GLP-2 (Figure 1d), suggesting a role for extracellular adenosine in this effect and also establishing a sequence of events, with adenosine operating downstream GLP-2. Since pre-administration of anti-IGF-1, MRS 1754 and APCP did not affect MRP2 activity in rats receiving oleic acid vehicle (data not shown), we ruled out any effect by these agents themselves. Adenosine per se, administered intravenously (10 mg/kg b.w.), significantly increased DNP-SG efflux (+222 $\%$; Figure 1d), confirming the ability of this nucleoside to modulate MRP2 activity when reaching the intestinal epithelium from the serosal side.

\subsubsection{The stimulus generated by oleic acid is transmitted along the intestinal wall}

After providing evidence supporting a role for specific mediators on the rapid action of oleic acid on MRP2 activity, the following question arose: how does the stimulus triggered by oleic acid in distal intestine reach the proximal jejunum? One possible transmission route is endocrine, with GLP-2 reaching systemic circulation after its release and finally acting at proximal jejunum. The other possibility is a transmission through the complex organization of neurons of the enteric nervous system, able to propagate stimuli in both 
oral and caudal directions. ${ }^{28}$ To distinguish between these possibilities, we sectioned the jejunum between the distal end of the intestinal sac and the site of administration of oleic acid, right before lipid administration. With this simple intervention, the neuronal connection between both regions of the jejunum is interrupted while the systemic connection remains unaffected. Figure $1 \mathrm{e}$ shows that jejunum sectioning limited the ability of oleic acid to enhance MRP2 activity. This finding is an unequivocal evidence of the participation of a transmission pathway that depends on the continuity of the intestine.

\subsubsection{Oleic acid acutely increases apical MRP2 localization by a GLP-2-mediated mechanism}

To assess whether these changes in MRP2 activity were correlated with changes in MRP2 subcellular localization, we performed a quantitative and qualitative confocal microscopy analysis. Figure 2 shows representative images of each group. In the upper panel images, channels corresponding to nuclei (blue) and MRP2 (red) are shown. The panels below show only the MRP2 channel in gray scale. The densitometric analysis is shown at the bottom. Acute, intraluminal treatment with oleic acid increased MRP2 sorting from intracellular compartments to the apical membrane, as evidenced by a less dispersed signal along of the enterocytic longitudinal axis and more focused signal on the BBM region when compared to control group. Consistent with this qualitative interpretation, analysis of densitometric curves results in significantly higher MRP2 peak height $(+185 \%)$ compared to control group. This higher density of transporter at the apical membrane of the enterocyte is in agreement with the reported increase in transport activity after oleic acid treatment. On the other hand, immunoneutralization of GLP-2 30 min before treatment resulted in images, densitometric curve and MRP2 peak height similar to those from control group, demonstrating the participation of GLP-2 in the proinsertor effect of oleic acid (Figure 2).

\subsection{In vitro studies: Elucidation of the intracellular mechanism involved in adenosine effects}

2.2.1. Adenosine acutely increases MRP2 activity in Caco-2 cells through A2BAR and PKA activation 
To elucidate the molecular mechanism downstream adenosine, we first confirmed the effect of this mediator on MRP2 activity through the evaluation of CDF efflux ratio across Caco-2 cell monolayers. Figure $3 a$ shows that acute treatment with adenosine $(50 \mu \mathrm{M})$ significantly increased CDF Papp in BA direction with respect to control cells, without changes in Papp in $A B$ direction. This led to a significant increase in CDF efflux ratio, confirming that adenosine is able to increase MRP2 activity also in this model (Figure $3 b)$. In addition, we demonstrated that this effect was mediated by the A2BAR receptor, since increases in both CDF Papp in BA direction and CDF efflux ratio were prevented by the selective inhibitor MRS 1754 (Figure 3). MRS 1754 itself had no effect on CDF efflux ratio (MRS group; data not shown).

Finally, we evaluated the participation of PKA in adenosine-mediated increase of MRP2 activity using KT5720. In the presence of this inhibitor, adenosine did not significantly modify CDF Papp in BA direction or CDF efflux ratio (Figure 3), confirming PKA mediation. However, because there were no differences between adenosine and adenosine + KT groups (Figure 3), PKA may not be the only mediator involved in the effects of adenosine. It is worth noting that KT5720 alone did not affect CDF efflux ratio, dismissing any possible unspecific effect of this agent in MRP2 activity (KT group; data not shown).

\subsubsection{Adenosine acutely increases apical MRP2 localization through A2BAR activation}

The next step was to assess whether the adenosine-dependent increase in MRP2 activity is associated to an increase in transporter apical insertion. Quantitative confocal microscopy studies showed that adenosine treatment (50 $\mu \mathrm{M}, 30 \mathrm{~min})$ significantly increased MRP2 peak height, which was also found to be markedly displaced towards the apical surface of the monolayer (Figure 4). Images corresponding to the Z-stack adequately illustrate this finding, since adenosine-treated cells show apical MRP2 concentration with concomitant decrease of the signal from intracellular regions when compared to control cells, which show a much more homogeneous MRP2 distribution along the $Z$ axis (Figure 4). Panels on the right show that MRS $1754(1 \mu \mathrm{M}$; A2BAR inhibitor) was able to prevent adenosine-induced changes in MRP2 distribution. These findings demonstrate that acute treatment with adenosine was able to stimulate 
translocation of MRP2 from intracellular reservoirs to the apical membrane, in an A2BARmediated fashion.

\subsubsection{Adenosine increases intracellular cAMP levels}

Finally, considering that A2BAR is coupled to Gs, an adenylate cyclase activating protein, we assessed the intracellular cAMP levels after adenosine treatment ( $50 \mu \mathrm{M} ; 15 \mathrm{~min})$. As result, we found a significant increase in Caco-2 cell lysates $(269.5 \pm 21.9 \mathrm{pmol} / \mathrm{mL}$ versus $206.7 \pm 6.4 \mathrm{pmol} / \mathrm{mL}$, respectively; $p<0.05, n=4$ ). 


\section{Discussion}

In this study we provide evidence supporting a novel physiological mechanism aimed at acutely regulating intestinal MRP2 activity in response to food intake, hence protecting the organism against the absorption of dietary toxicants. After our recent proof-of-concept article demonstrating the short-term regulation of intestinal MRP2, ${ }^{22}$ we focused on the development of an in vivo model with preserved irrigation and innervation that allows for detection of changes in MRP2 activity and localization in response to intraluminal administration of nutrients (section 4.2.2). This model was validated using the proinsertor agent dbcAMP (Figure 1a), intravenously administered at a dose known to be effective in modulating MRP2 in another highly perfused organ such as the liver. ${ }^{29}$ The differential effect of intraluminally administered agents on MRP2 activity (Figure 1b) is consistent with previous evidence demonstrating that GLP-2 secretion depends on the specific nutrient composition of the diet.23 Glucose exerted a dose-dependent action, with no effect at $10 \mathrm{mM}$ and a statistically significant increase at $100 \mathrm{mM}$ concentration (Figure 1b). Considering that the intrajejunal glucose concentration after a meal ranges between 0.4 and $24 \mathrm{mM}$ in rats and between 0.5 and $40 \mathrm{mM}$ in humans, depending whether it is distal or proximal jejunum, ${ }^{25}$ our finding at $100 \mathrm{mM}$ may not have physiological relevance. Regarding glutamine, the work of Reimann et al. ${ }^{30}$ demonstrated the ability of a $10 \mathrm{mM}$ concentration to stimulate GLP-1 secretion in an in vitro model. Since GLP-1 is cosecreted with GLP-2 in equimolar amounts, this finding provided a rationale for inclusion of glutamine in the list of nutrients to be evaluated. However, the negative results (Figure 1b) are rather aligned with in vivo studies ruling out a stimulatory effect of proteins and amino acids on GLP-2 secretion. ${ }^{20,31}$ Of the highest significance is the maximal response on MRP2 activity registered after oleic acid treatment (Figure 1b) at a physiologically relevant concentration. ${ }^{24}$ This led us to select this nutrient as the prototype to be used for the subsequent in vivo studies. This increase in transport activity was associated with MRP2 insertion on the apical membrane, evidenced by a higher MRP2 peak localized to the apical end of enterocytes and concomitant weaker signal from intracellular regions (Figure 2).

The participation of GLP-2 in oleic acid effect was demonstrated using an immunoneutralization method, originally reported in a work linking GLP-2 with adaptative 
intestinal growth secondary to streptozotocin-induced diabetes. ${ }^{32}$ This finding, supported by the effect of intravenously administered GLP-2 on MRP2 activity (Figure 1c), constitutes a new item in the increasing list of GLP-2 biological functions at the intestinal level.8,11,12,33-36 Regarding the molecular mechanism that follows GLP-2 secretion, we first evaluated the participation of IGF-1. This growth factor, although closely linked to GLP-2 actions, was mainly associated with long-term effects such as proliferation and intestinal growth. ${ }^{14}$ Immunoneutralization of IGF-1 was unable to block the stimulating effect of oleic acid on MRP2 activity (Figure 1d). This would mean either that IGF-1 is not involved downstream GLP-2 or that the treatment was not effective enough to completely abolish IGF-1 activity. Additional experiments are required to properly distinguish between these two possibilities. In contrast, we identified adenosine as a valid candidate based on the results obtained using APCP (Figure 1d). Moreover, the evidence strongly suggests that extracellular adenosine synthesis by CD73 is a prerequisite for the effect of both oleic acid and GLP-2 on MRP2 activity. CD73, also known as ecto-5'-nucleotidase, mediates the generation of extracellular adenosine at the intestinal level.26,27 This process, of central role in both physiological and pathophysiological conditions, begins with ATP released by enteric neurons from submucosal and/or myenteric plexuses. ${ }^{37}$ ATP is then hydrolyzed by different ecto-nucleoside triphosphate diphosphohydrolases yielding AMP, which is further dephosphorylated to adenosine by CD73. ${ }^{38}$ cAMP was suggested as an alternative precursor to ATP in extracellular adenosine synthesis, in this case by tandem action of ecto-phosphodiesterase and CD73. ${ }^{27}$ With our experimental strategy it is not possible to ascertain whether ATP or CAMP constitutes the initial substrate in the cascade that culminates with CD73-dependent adenosine synthesis (Figure 5). Although we cannot rule out the participation of additional mediators such as IGF-1, it is noteworthy that the administration of either APCP or MRS 1754 (Figure 1d) was capable of abolishing oleic acid stimulation of MRP2 activity. This is consistent with a major role for GLP-2/extracellular adenosine/A2BAR pathway in oleic acid effects. Finally, experiments involving sectioning of the intestine demonstrate that the effects reported for oleic acid totally depended on the preservation of the structure and continuity of the intestinal wall, indirectly ruling out the intervention of systemic circulation (Figure 1e). Considering both GLP-2R expression in enteric neurons ${ }^{13}$ and the deep innervation of intestinal epithelial cells by these neurons, ${ }^{39}$ the hypothesis of a transmission through the 
multiple neurons from submucosal and/or myenteric plexuses seems the most likely. Figure 5 illustrates only one of the possibilities, since other more complex alternatives to the one represented, such as the participation of more than one neuronal type, cannot be ruled out. In this regard, signal transmission in caudal-oral direction may involve intrinsic primary afferent neurons, ascending interneurons and motor neurons. ${ }^{28}$ Additional experiments including synaptic transmission blockades may contribute to clarify this route.

Due to the technical difficulties inherent in establishing a primary enterocyte culture, Caco-2 intestinal cells were chosen to evaluate the intracellular mechanism. Despite their colonic origin, Caco-2 cells undergo spontaneous differentiation after 21 days of culture to form a confluent monolayer of enterocyte-like polarized cells, which structurally and functionally resembles the small intestinal epithelium. ${ }^{40-42}$ Regarding expression of the most relevant intestinal transporters (including MRP2), different studies demonstrated a similar pattern between differentiated Caco-2 cells and human small intestine. ${ }^{43-45}$ Thus, Caco-2 cell monolayers grown on permeable supports constitute an optimal in vitro model system for drug transport studies. ${ }^{40}$ In addition, using confocal microscopy and membrane fractionation followed by immunoblotting studies, rapid changes in MRP2 localization were already confirmed in these cells. ${ }^{22}$ In the current work we demonstrated that acute treatment with adenosine led to a significant increase in MRP2 activity (Figure 3b) which was associated with apical insertion of the transporter (Figure 4). These findings complement those resulting from in vivo studies (Figure 1d), and demonstrate for the first time adenosine modulatory action on both human and murine intestinal MRP2. Interestingly, interstitial adenosine levels in the jejunum are increased up to two orders of magnitude during post-intake periods, a situation so far associated with postprandial jejunal hyperemia. ${ }^{46,47}$ Based on our findings, we suggest that postprandial adenosine boost not only leads to increased intestinal blood flow but also contributes to strengthen the intestinal barrier function provided by MRP2.

The effect of adenosine on MRP2 activity and localization in Caco-2 cells was mediated by A2BAR (Figure 3 and Figure 4). Within adenosine receptors, A2BAR is the most relevant in the intestine and is expressed, among other sites, at epithelial level. ${ }^{48,49}$ Since it is coupled to $G$ stimulatory protein, an increase in cAMP synthesis by adenylate cyclase after activation is expected. In fact, studies using T84 intestinal epithelial cell 
monolayers demonstrated that activation of A2BAR/CAMP/PKA axis by adenosine stimulates polarized apical secretion of the proinflammatory cytokine IL-6.50 Considering that several compounds with proinflammatory activity such as prostaglandins or leukotrienes are MRP2 substrates, ${ }^{1,2}$ it is possible that this regulation takes place also under pathophysiological conditions, e.g. to deal with intraluminal pathogens. In our experimental conditions, intracellular levels of CAMP were also significantly increased in response to adenosine stimulation after a 15-min treatment (section 2.2.3). This result provides evidence in support of adenosine/A2BAR/adenylate cyclase axis functionality in our experimental model. We also found that PKA participation is necessary to explain, at least in part, modulation of MRP2 activity by adenosine (Figure 3). These findings agree with previous evidence in hepatic and intestinal models demonstrating the ability of CAMP/PKA axis to acutely increase MRP2 activity.22,51 However, it is important to note that CAMP increase not only leads to PKA activation, but can also increase the activity of other kinases such as exchange protein directly activated by cAMP, phosphoinositide 3kinase or p38 mitogen-activated protein kinases, all of them also able to acutely modulate MRP2 localization in hepatic models. ${ }^{51}$ Additional studies are necessary to further determine the eventual participation of kinases other than PKA.

Our in vivo model allows for evaluation of the effect of GLP-2 produced only by direct stimulation of $L$ cells by nutrients, and does not consider the effect of GLP-2 produced by indirect mechanisms in response to the presence of nutrients in the duodenum. This mechanism involving participation of vagal fibers and nicotinic synapses ${ }^{18}$ results in earlier $L$ cell stimulation and complements the effect here described. Regarding the time of permanence of nutrients in the small intestine, a transit time between one and four hours has been estimated, regardless of whether they are originated in solid or liquid foods. ${ }^{52}$ Sustained secretion of GLP-2 along the whole digestive process would provide an enhanced barrier function in order to deal with the exposition to potentially harmful components of the diet.

Because of its preferential localization at the proximal region of the small intestine, MRP2 exerts a significant function in reducing the body load of potentially harmful compounds entering the digestive tract. Although with different distribution along the intestine, other $A B C$ transporters expressed at the BBM of the enterocyte provide a similar barrier function. ${ }^{53}$ In the current study, we have only explored the regulation of MRP2 by 
nutrients and cannot ascertain whether other members of the $A B C$ family would be affected in a similar fashion. To our knowledge, there is no information in the literature describing such effect. If demonstrated, it would represent a regulation complementary to MRP2 since a broader substrate specificity and a more extensive intestinal region will be covered. In addition to the barrier function, this physiological mechanism could also improve nutrient absorption during the course of a meal if demonstrated for intestinal uptake proteins such as solute carrier transporters. In this regard, Cheeseman made a substantial contribution by reporting increased sodium-dependent glucose uptake in rat jejunum BBM vesicles after 30 min of GLP-2 intravenous treatment. This was associated with increased SGLT-1 localization in BBM. Based on the results obtained using wortmannin, the author proposes phosphoinositide 3-kinase as the mediator of this acute GLP-2 effect. ${ }^{54}$

The main conclusion of this work is summarized in Figure 5. After intake, the presence of nutrients such as oleic acid in the intestinal lumen triggers GLP-2 release by enteroendocrine L cells, presumably by both indirect and direct mechanisms. GLP-2, secreted through the basolateral membrane into the interstitial space, would activate its receptor in enteric neurons. As a consequence, the generated stimulus would be transmitted along the intestinal wall, eventually involving participation of more neurons or other cellular types. AMP precursors such as ATP or cAMP are likely secreted by these neurons, although the intervention of some other cell type in the proximity of the enterocyte cannot be ruled out. AMP is then hydrolyzed by CD73 yielding adenosine, which directly activates A2BAR at the basolateral membrane of the enterocyte. This activation results in increased intracellular cAMP concentrations, ultimately stimulating MRP2 insertion from intracellular reservoirs to BBM in a process mediated, at least in part, by PKA. This increase in MRP2 density at the apical membrane is associated with increased transport activity and thus increased membrane barrier function. An additional contribution of our study is that, during fasting periods, GLP-2- MRP2 interaction is expected to decrease due to absence of stimuli on intestinal $L$ cells. This event, also physiologic, would result in decreased MRP2 apical localization and activity, saving metabolic energy and avoiding the unnecessary luminal secretion of valuable substrates such as glutathione, essential for cellular homeostasis maintenance. 


\section{Materials and Methods}

\subsection{Chemicals}

Adenosine, adenosine 5'-( $\alpha, \beta$-methylene) diphosphate (APCP), 5(6)-carboxy-2',7'dichlorofluorescein diacetate (CDFDA), 1-chloro-2,4-dinitrobenzene (CDNB), dbcAMP, glucose, glutamine and MRS 1754 were purchased from Sigma-Aldrich (Missouri, USA); anti-GLP-2 (C-20) and KT5720 were purchased from Santa Cruz Biotechnology (Dallas, USA); anti-IGF-1 (M23) was purchased from ThermoScientific (Illinois, USA); rat recombinant GLP-2 was purchased from Abcam (Cambridge, UK) and double-distilled oleic acid was purchased from Ballester Productos Químicos S.A. (Villa Ballester, Argentina). DNP-SG was synthesized using 1-fluoro-2,4-dinitrobenzene and glutathione as described by Sokolovsky et al. ${ }^{55}$ All other chemicals were of analytical grade purity or higher.

\subsection{In vivo studies}

\subsubsection{Animals}

Adult male Wistar rats (310 - $330 \mathrm{~g})$ were supplied by Centro de Medicina Comparada (UNL - CONICET, Esperanza, Argentina). They were maintained with a standard diet and tap water ad libitum in a room with controlled temperature and humidity and a 12-12 $\mathrm{h}$ light-dark cycle. The rats were fasted for 12 hours before the experiments. At the time of the experiments, they were anesthetized using ketamine + xylazine (ketamine: $100 \mathrm{mg} / \mathrm{kg}$ b.w; xylazine: $15 \mathrm{mg} / \mathrm{kg}$ b.w.; i.p) and, after that, their body temperature was monitored and maintained between $37^{\circ} \mathrm{C}$ and $37.5^{\circ} \mathrm{C}$ using heating lamps. All procedures involving animals were in accordance with the 'European Convention for the Protection of Vertebrate Animals used for Experimental and Other Scientific Purposes' and were approved by the Bioethical Committee for the Management of Laboratory Animals from the Faculty of Biochemical and Pharmaceutical Sciences of the National University of Rosario (Res. 410/2014).

\subsubsection{In vivo model}

The in vivo model used in this work allows for direct stimulation of GLP-2-producing L cells in the intestinal region in which their presence is maximal (distal jejunum, ileum and 
colon) with simultaneous evaluation of MRP2 activity and localization in the intestinal region exhibiting the highest MRP2 expression (proximal jejunum) (see Figure 6a). In addition, this model preserves intestinal irrigation and innervation.

\subsubsection{Intraluminal and intravenous treatments}

To evaluate the effect of GLP-2 secretion stimulators on MRP2 activity and localization, $2.5 \mathrm{~mL}$ of oleic acid ( $10 \% \mathrm{~V} / \mathrm{V}$ in saline $+3 \%$ Tween $20 ; \mathrm{pH}=6.5),{ }^{24}$ glucose (10 and $100 \mathrm{mM}$ in saline, $\mathrm{pH}=6.5),{ }^{56}$ glutamine $(10$ and $100 \mathrm{mM}$ in saline, $\mathrm{pH}=6.5),{ }^{30}$ saline + $3 \%$ Tween 20 or saline alone were gently injected into distal jejunum (approximately 19 $\mathrm{cm}$ after the ligament of Treitz) using a 25G needle. During this procedure, the region of the intestine proximal to the site of administration was occluded with a thread to avoid retrograde flow of the agents. After 20 min of treatment, MRP2 activity studies were performed.

For systemic treatments, the femoral vein was catheterized with polyethylene tubing (PE-

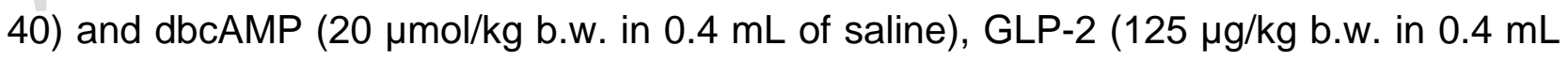
of saline), adenosine (10 mg/kg b.w. in $0.4 \mathrm{~mL}$ of saline) or saline alone were administered.29,57,58 After 20 min, MRP2 activity studies were performed. In the case of adenosine, the total volume was administered in four doses of $0.1 \mathrm{~mL}$ each, with 5 -min intervals. All these procedures are illustrated in Figure $6 \mathrm{~b}$.

To gain insight into the mechanism of stimulation by oleic acid, immunoneutralization of GLP-2 and IGF-1 was performed by intraperitoneal injections of anti-GLP-2 (20 $\mu \mathrm{g}$ in 1 $\mathrm{mL}$ of saline) or anti-IGF-1 (50 $\mathrm{gg}$ in $1 \mathrm{~mL}$ of saline) respectively, $30 \mathrm{~min}$ before administration of this nutrient. ${ }^{32}$ Identical experiments of immunoneutralization with antiIGF-1 and anti-GLP-2 were performed with animals receiving only the vehicle of oleic acid. To evaluate the participation of extracellular adenosine in the signaling mechanism, the selective CD73 inhibitor APCP ( $2 \mathrm{mg} / \mathrm{kg}$ b.w. in $1 \mathrm{~mL}$ of saline) and the selective A2B adenosine receptor (A2BAR) inhibitor MRS $1754(0.5 \mathrm{mg} / \mathrm{kg} \mathrm{b.w}$. in $1 \mathrm{~mL}$ of saline) were intraperitoneally administered $30 \mathrm{~min}$ before administration of oleic acid or GLP-2.59,60 Identical experiments of inhibition with APCP and MRS 1754 were performed replacing oleic acid and GLP-2 by the respective vehicles. Finally, to evaluate the participation of the local nervous system, the intestine was sectioned $2 \mathrm{~cm}$ proximal to the site of nutrient 
administration (i.e. approximately $17 \mathrm{~cm}$ after the ligament of Treitz), just before intraluminal treatment with oleic acid. All these procedures are illustrated in Figure 6c.

\subsubsection{MRP2 activity studies}

During the $20-\mathrm{min}$ treatments, the $15-\mathrm{cm}$ proximal jejunum segment for evaluation of DNP-SG (i.e. model substrate of MRP2) efflux was delimited. The proximal and distal ends of this segment (located $1 \mathrm{~cm}$ and $16 \mathrm{~cm}$ after the ligament of Treitz, respectively) were identified with pre-assembled, untied knots. Once the treatment was completed, the distal end knot was tied, the segment was filled with $2.6 \mathrm{~mL}$ of a $100 \mu \mathrm{M}$ CDNB solution in Krebs-Henseleit buffer and finally the proximal end knot was tied, completely closing the intestinal sac. The incubation time under these conditions was $30 \mathrm{~min}$. Afterwards, the animal was sacrificed by exsanguination and the intestinal sac was removed. After sac length measurement, the content was collected in a graduated tube and its volume was recorded. After deproteinization, the solution was subjected to quantification of DNPSG and its dinitrophenyl-cysteinyl glycine derivative (DNP-CG) by HPLC-UV as previously described.61 DNP-SG + DNP-CG mass was calculated using their concentration and the volume measurements of the intestinal sac content. DNP-CG is produced by the action of $\mathrm{Y}$-glutamyltransferase on DNP-SG at the BBM after this compound reaches the mucosal compartment. ${ }^{62}$ Therefore, the excretion rate of DNP-SG + DNP-CG adequately estimates MRP2 activity. These procedures are summarized in Figure 6d.

\subsubsection{MRP2 localization studies}

MRP2 localization studies were performed by immunostaining followed by quantitative confocal microscopy. Rats were treated with intraluminal saline (control group), intraluminal oleic acid (oleic acid group) or intraluminal oleic acid with anti-GLP-2 pretreatment (oleic acid + anti-GLP-2 group) as previously described. After sacrifice by exsanguination, a segment from proximal jejunum was carefully washed and frozen in liquid 1,1,1,2-tetrafluoroethane (Electroquímica DELTA SRL, Buenos Aires, Argentina). The segment was cut into slices of $5 \mu \mathrm{m}$ thick with a microtome cryostat (HM 500, Microm International $\mathrm{GmbH}$, Walldorf, Germany) and mounted on slides. Preparations were fixed, permeabilized and blocked as previously described. ${ }^{63}$ MRP2 was detected 
using anti-MRP2: M2III-6 (1:100) from Enzo Life Sciences (Farmingdale, USA) followed by incubation with anti-mouse IgG conjugated with Alexa Fluor 555 (1:300) from ThermoScientific (Illinois, USA). Nuclei were detected using Hoechst 33258 from Santa Cruz Biotechnology (Dallas, USA). At least 8 images per group were captured using a Nikon $\mathrm{C} 1+$ confocal system built onto a Nikon TE2000 inverted microscope with a 60X Plan Apo NA 1.4 objective. Images were then analyzed using ImageJ software $(\mathrm{NIH}$, Bethesda, USA). To establish the relative MRP2 distribution with respect to the nuclei, MRP2 and nuclei channels were separated and the distribution of the fluorescence intensity along the longitudinal axis of the enterocyte was evaluated (see Figure 7 ). The total area under the curves were assigned the same arbitrary value and the maximum value of MRP2 fluorescence intensity (peak height) was compared between groups as a quantitative measurement of MRP2 distribution. For data presentation, maximum fluorescence intensity values of the nuclei were aligned to qualitatively reveal eventual changes in MRP2 cellular distribution in response to treatments.

\subsection{In vitro studies}

\subsubsection{Caco-2 cell culture}

Caco-2 cells were obtained from the American Tissue Culture Collection (Manassas, USA) and grown in DMEM (Gibco; Carlsbad, USA) supplemented with 10\% V/V fetal bovine serum (Natocor; Córdoba, Argentina), 1 \% V/V non-essential amino acids, $2 \mathrm{mM}$ L-glutamine, $100 \mathrm{U} / \mathrm{mL}$ penicillin and $100 \mu \mathrm{g} / \mathrm{mL}$ streptomycin (Gibco; Carlsbad, USA). Cells were grown at $37^{\circ} \mathrm{C}$ in a humid atmosphere containing $5 \% \mathrm{CO}_{2}$.

\subsubsection{MRP2 activity studies}

For MRP2 activity studies, $3 \times 10^{5}$ cells/well were seeded in 12-well Transwell ${ }^{\circledR}$ permeable supports (cat. No. 3401; Corning Inc., Corning, USA) and cultured for 21 days as described by Hubatsch et al. ${ }^{40}$ Culture medium in both apical and basolateral compartments was replaced every second day. To evaluate monolayer integrity, transepithelial electrical resistance (TEER) was monitored every second day using an epithelial voltohmmeter (EVOM; World Precision Instruments, Sarasota, USA). All cell monolayers used in the experiments had TEER values at $37^{\circ} \mathrm{C}$ above $300 \Omega \mathrm{cm}^{2}$, indicating a continuous monolayer. ${ }^{40}$ 
MRP2 activity was evaluated by assessing the ratio between the apical-to-basolateral $(\mathrm{AB})$ and the basolateral-to-apical $(\mathrm{BA})$ directional transport of the prototypical MRP2 substrate 5(6)-carboxy-2',7'-dichlorofluorescein (CDF) as previously described. ${ }^{61}$ The CDF non-fluorescent promoiety, CDFDA, is taken up passively by Caco-2 cells and immediately hydrolyzed by intracellular esterases to the fluorescent CDF. ${ }^{64}$ Briefly, prior to the activity measurement, cell monolayers were washed with Hank's balanced salt solution (HBSS) for $15 \mathrm{~min}$ at $37^{\circ} \mathrm{C}$. Afterwards, cells were treated with culture medium alone (control group) or culture medium containing $50 \mu \mathrm{M}$ adenosine (adenosine group), $50 \mu \mathrm{M}$ adenosine $+10 \mu \mathrm{M}$ MRS 1754 (adenosine + MRS group), $50 \mu \mathrm{M}$ adenosine +1 $\mu \mathrm{M}$ KT5720 (adenosine + KT group), $10 \mu \mathrm{M}$ MRS 1754 (MRS group) or $1 \mu \mathrm{M}$ KT5720 (KT group). ${ }^{22,65,66}$ After 20 min of treatment, cells were washed with HBSS alone (control group) or HBSS containing $50 \mu \mathrm{M}$ adenosine (adenosine group), $50 \mu \mathrm{M}$ adenosine +10 $\mu \mathrm{M}$ MRS 1754 (adenosine + MRS group), $50 \mu \mathrm{M}$ adenosine + $1 \mu \mathrm{M}$ KT5720 (adenosine + KT group), $10 \mu \mathrm{M}$ MRS 1754 (MRS group) or $1 \mu \mathrm{M} \mathrm{KT5720} \mathrm{(KT} \mathrm{group)} \mathrm{for} 15 \mathrm{~min}$ at $37^{\circ} \mathrm{C}$. Then, filter inserts were transferred to new plates and CDFDA $(10 \mu \mathrm{M}$, in HBSS) was added to the donor compartment (apical for $A B$ direction experiments, basolateral for $B A$ direction experiments). The receiving compartment (basolateral for $A B$ direction experiments, apical for BA direction experiments) was filled with pre-warmed HBSS. Plates were then placed in a $37^{\circ} \mathrm{C}$ incubator and samples from the receiving compartment were withdrawn with volume replacement every $30 \mathrm{~min}$ up to $120 \mathrm{~min}$. CDF was quantified using a DTX 880 fluorometer (Beckman Coulter; Brea, USA) set at 485 $\mathrm{nm} / 520 \mathrm{~nm}$ for excitation and emission wavelengths, respectively. Apparent permeability coefficients $\left(\mathrm{P}_{\mathrm{app}}, \mathrm{cm} \cdot \mathrm{s}^{-1}\right)$ of CDF across cell monolayers in both $A B$ and $B A$ directions were calculated using the following equation:

$$
\text { Papp }=\frac{1}{\mathrm{C}^{0} \mathrm{~A}} \times \frac{\mathrm{dQ}}{\mathrm{dt}}
$$

where $d Q / d t$ is the appearance rate of CDF on the receiving compartment, $C_{0}$ is the initial CDFDA concentration in the donor compartment $(10 \mu \mathrm{M})$ and $A$ is the Transwell ${ }^{\circledR}$ support surface area $\left(1.12 \mathrm{~cm}^{2}\right)$. CDF efflux ratio was obtained by dividing $P_{\text {app }}$ in the $B A$ direction by $\mathrm{P}_{\text {app }}$ in the $\mathrm{AB}$ direction.

\subsubsection{MRP2 localization studies}


To detect MRP2 localization in Caco-2 cells, a sterile coverslip was placed in each well of 6 -well plates; $2.5 \times 10^{5}$ cells were seeded on each coverslip and cultured for 21 days as described. Then, differentiated cells were treated with culture medium alone (control group) or culture medium containing $50 \mu \mathrm{M}$ adenosine (adenosine group) or $50 \mu \mathrm{M}$ adenosine + $10 \mu \mathrm{M}$ MRS 1754 (adenosine + MRS group). After $30 \mathrm{~min}$ of treatment, immunostaining of MRP2 and nuclei was performed as described earlier in this section. Optical sections (23-31 z-series) were collected with a step size of $0.4 \mu \mathrm{m}$. Images are shown as top and 3D orthogonal views. The densitometric study was similar to that performed for intestinal segments, except that the determination of fluorescence intensity was performed along the $z$ axis, using a $10 \mu \mathrm{m}$ line.

\subsubsection{Quantification of intracellular cAMP}

To quantify intracellular levels of cAMP, $2.5 \times 10^{5}$ cells/well were seeded in 6-well plates and cultured for 21 days. Then, they were incubated with culture medium alone (control group) or culture medium containing $50 \mu \mathrm{M}$ adenosine (adenosine group) for $15 \mathrm{~min}$. Immediately afterwards, cells were washed with PBS and lysed in $\mathrm{HCl}(0.1 \mathrm{M}, 20 \mathrm{~min})$ at room temperature in order to stop phosphodiesterase activity and stabilize the released cAMP. ${ }^{67,68}$ Finally, CAMP was quantified using the cAMP Select ELISA kit (Cayman Chemical, Ann Arbor, USA) according to the manufacturer's instructions.

\subsection{Statistical analysis}

All results were expressed as mean \pm standard deviation. Statistical comparisons were performed through the Student's t-test (two experimental groups) or through ANOVA followed by Tukey (more than two experimental groups). Statistical significance was set at $p<0.05$. 


\section{Acknowledgements}

The authors would like to thank Marcelo Gabriel Luquita and José Manuel Pellegrino for their excellent technical assistance. This work was supported by grants from National Agency of Promotion of Science and Technology (ANPCyT) to ADM (PICT 2017-1098) and MLR (PICT 2016-1664). 


\section{Data availability statement}

The data that support the findings of this study are available from the corresponding author upon reasonable request. 


\section{Conflict of interest}

The authors declare that they have no conflict of interest. 


\section{References}

1. Estudante M, Morais JG, Soveral G, Benet LZ. Intestinal drug transporters: an overview. Adv Drug Deliv Rev. 2013;65:1340-1356.

2. Chen Z, Shi T, Zhang L, Zhu P, Deng M, Huang C, Hu T, Jiang L, Li J. Mammalian drug efflux transporters of the ATP binding cassette $(A B C)$ family in multidrug resistance: $A$ review of the past decade. Cancer Lett. 2016;370:153-164.

3. Gotoh Y, Suzuki H, Kinoshita S, Hirohashi T, Kato Y, Sugiyama Y. Involvement of an organic anion transporter (canalicular multispecific organic anion transporter/multidrug resistance-associated protein 2) in gastrointestinal secretion of glutathione conjugates in rats. J Pharmacol Exp Ther. 2000;292:433-439.

4. Mottino AD, Hoffman T, Jennes L, Vore M. Expression and localization of multidrug resistant protein mrp2 in rat small intestine. J Pharmacol Exp Ther. 2000;293:717-723.

5. Nakamura T, Sakaeda T, Ohmoto N, Tamura T, Aoyama N, Shirakawa T, Kamigaki T, Nakamura T, Kim KI, Kim SR, Kuroda Y, Matsuo M, Kasuga M, Okumura K. Real-time quantitative polymerase chain reaction for MDR1, MRP1, MRP2, and CYP3A-mRNA levels in Caco-2 cell lines, human duodenal enterocytes, normal colorectal tissues, and colorectal adenocarcinomas. Drug Metab Dispos. 2002;30:4-6.

6. Cao X, Gibbs ST, Fang L, Miller HA, Landowski CP, Shin HC, Lennernas H, Zhong Y, Amidon GL, Yu LX, Sun D. Why is it challenging to predict intestinal drug absorption and oral bioavailability in human using rat model. Pharm Res. 2006;23:1675-1686.

7. Dietrich CG, de Waart DR, Ottenhoff R, Schoots IG, Elferink RP. Increased bioavailability of the food-derived carcinogen 2-amino-1-methyl-6-phenylimidazo[4,5-b]pyridine in MRP2-deficient rats. Mol Pharmacol. 2001;59:974-980.

8. Drucker DJ, Erlich P, Asa SL, Brubaker PL. Induction of intestinal epithelial proliferation by glucagon-like peptide 2. Proc Natl Acad Sci U S A. 1996;93:7911-7916.

9. Tsai $\mathrm{CH}$, Hill M, Asa SL, Brubaker PL, Drucker DJ. Intestinal growth-promoting properties of glucagon-like peptide-2 in mice. Am J Physiol. 1997;273:E77-E84.

10. Litvak DA, Hellmich MR, Evers BM, Banker NA, Townsend CM Jr. Glucagon-like peptide 2 is a potent growth factor for small intestine and colon. J Gastrointest Surg. 1998;2:146150. 
11. Guan X, Karpen HE, Stephens J, Bukowski JT, Niu S, Zhang G, Stoll B, Finegold MJ, Holst JJ, Hadsell D, Nichols BL, Burrin DG. GLP-2 receptor localizes to enteric neurons and endocrine cells expressing vasoactive peptides and mediates increased blood flow. Gastroenterology. 2006;130:150-164.

12. Stephens J, Stoll B, Cottrell J, Chang X, Helmrath M, Burrin DG. Glucagon-like peptide-2 acutely increases proximal small intestinal blood flow in TPN-fed neonatal piglets. $\mathrm{Am} \mathrm{J}$ Physiol Regul Integr Comp Physiol. 2006;290:R283-R289.

13. Dubé PE, Brubaker PL. Frontiers in glucagon-like peptide-2: multiple actions, multiple mediators. Am J Physiol Endocrinol Metab. 2007;293:E460-E465.

14. Dubé PE, Forse CL, Bahrami J, Brubaker PL. The essential role of insulin-like growth factor-1 in the intestinal tropic effects of glucagon-like peptide-2 in mice. Gastroenterology. 2006;131:589-605.

15. Dubé PE, Rowland KJ, Brubaker PL. Glucagon-like peptide-2 activates beta-catenin signaling in the mouse intestinal crypt: role of insulin-like growth factor-I. Endocrinology. 2008;149:291-301.

16. Lee J, Koehler J, Yusta B, Bahrami J, Matthews D, Rafii M, Pencharz PB, Drucker DJ. Enteroendocrine-derived glucagon-like peptide-2 controls intestinal amino acid transport. Mol Metab. 2017;6:245-255.

17. Matheson PJ, Li N, Harris PD, Zakaria el R, Garrison RN. Glucose-induced intestinal vasodilation via adenosine $\mathrm{A} 1$ receptors requires nitric oxide but not $\mathrm{K}(+)(\mathrm{ATP})$ channels. J Surg Res. 2011;168:179-187.

18. Anini $Y$, Brubaker PL. Muscarinic receptors control glucagon-like peptide 1 secretion by human endocrine L cells. Endocrinology. 2003;144:3244-3250.

19. Rocca AS, Brubaker PL. Role of the vagus nerve in mediating proximal nutrient-induced glucagon-like peptide-1 secretion. Endocrinology. 1999;140:1687-1694.

20. Xiao Q, Boushey RP, Drucker DJ, Brubaker PL. Secretion of the intestinotropic hormone glucagon-like peptide 2 is differentially regulated by nutrients in humans. Gastroenterology. 1999;117:99-105. 
21. Villanueva SS, Arias A, Ruiz ML, Rigalli JP, Pellegrino JM, Vore M, Catania VA, Mottino $A D$. Induction of intestinal multidrug resistance-associated protein 2 by glucagon-like Peptide 2 in the rat. J Pharmacol Exp Ther. 2010;335:332-341.

22. Tocchetti GN, Arias A, Arana MR, Rigalli JP, Domínguez CJ, Zecchinati F, Ruiz ML, Villanueva SSM, Mottino AD. Acute regulation of multidrug resistance-associated protein 2 localization and activity by CAMP and estradiol-17 $\beta$-D-glucuronide in rat intestine and Caco-2 cells. Arch Toxicol. 2018;92:777-788.

23. Dubé PE, Brubaker PL. Nutrient, neural and endocrine control of glucagon-like peptide secretion. Horm Metab Res. 2004;36:755-760.

24. lakoubov R, Ahmed A, Lauffer LM, Bazinet RP, Brubaker PL. Essential role for protein kinase $C \zeta$ in oleid acid-induced glucagon-like peptide-1 secretion in vivo in the rat. Endocrinology. 2011;152:1244-1252.

25. Soergel KH. Showdown at the tight junction. Gastroenterology. 1993;105:1247-1250.

26. Strohmeier GR, Lencer WI, Patapoff TW, Thompson LF, Carlson SL, Moe SJ, Carnes DK, Mrsny RJ, Madara JL. Surface expression, polarization, and functional significance of CD73 in human intestinal epithelia. J Clin Invest. 1997;99:2588-2601.

27. Giron MC, Bin A, Brun P, Etteri S, Bolego C, Florio C, Gaion RM. Cyclic AMP in rat ileum: evidence for the presence of an extracellular cyclic AMP-adenosine pathway. Gastroenterology. 2008;134:1116-1126.

28. Mazzone A, Farrugia G. Evolving concepts in the cellular control of gastrointestinal motility: neurogastroenterology and enteric sciences. Gastroenterol Clin North Am. 2007;36:499-513.

29. Mottino AD, Cao J, Veggi LM, Crocenzi F, Roma MG, Vore M. Altered localization and activity of canalicular Mrp2 in estradiol-17beta-D-glucuronide-induced cholestasis. Hepatology. 2002;35:1409-1419.

30. Reimann F, Williams L, da Silva Xavier G, Rutter GA, Gribble FM. Glutamine potently stimulates glucagon-like peptide-1 secretion from GLUTag cells. Diabetologia. 2004:47:1592-1601. 
31. Elliot JL, Oldham JM, Ambler GR, Molan PC, Spencer GS, Hodgkinson SC, Breier BH, Gluckman PD, Suttie JM, Bass JJ. Receptors for insulin-like growth factor-II in the growing tip of the deer antler. J Endocrinol. 1993;138:233-242.

32. Hartmann B, Thulesen J, Hare KJ, Kissow H, Orskov C, Poulsen SS, Holst JJ. Immunoneutralization of endogenous glucagon-like peptide-2 reduces adaptive intestinal growth in diabetic rats. Regul Pept. 2002;105:173-179.

33. Brubaker PL, Izzo A, Hill M, Drucker DJ. Intestinal function in mice with small bowel growth induced by glucagon-like peptide-2. Am J Physiol. 1997;272:E1050-E1058.

34. Drucker DJ. Biologic actions and therapeutic potential of the proglucagon-derived peptides. Nat Clin Pract Endocrinol Metab. 2005;1:22-31.

35. Drucker DJ, Yusta B. Physiology and pharmacology of the enteroendocrine hormone glucagon-like peptide-2. Annu Rev Physiol. 2014;76:561-583.

36. Markovic MA, Brubaker PL. The roles of glucagon-like peptide-2 and the intestinal epithelial insulin-like growth factor-1 receptor in regulating microvillus length. Sci Rep. 2019;9:13010.

37. Burnstock G. Purinergic cotransmission. Exp Physiol. 2009;94:20-24.

38. Cardoso AM, Schetinger MR, Correia-de-Sá P, Sévigny J. Impact of ectonucleotidases in autonomic nervous functions. Auton Neurosci. 2015;191:25-38.

39. Bjerknes $\mathrm{M}$, Cheng $\mathrm{H}$. Modulation of specific intestinal epithelial progenitors by enteric neurons. Proc Natl Acad Sci U S A. 2001;98:12497-12502.

40. Hubatsch I, Ragnarsson EG, Artursson P. Determination of drug permeability and prediction of drug absorption in Caco-2 monolayers. Nat Protoc. 2007;2:2111-2119.

41. Hidalgo IJ, Raub TJ, Borchardt RT. Characterization of the human colon carcinoma cell line (Caco-2) as a model system for intestinal epithelial permeability. Gastroenterology. 1989;96:736-749.

42. Hilgers AR, Conradi RA, Burton PS. Caco-2 cell monolayers as a model for drug transport across the intestinal mucosa. Pharm Res. 1990;7:902-910.

43. Englund G, Rorsman F, Rönnblom A, Karlbom U, Lazorova L, Gråsjö J, Kindmark A, Artursson P. Regional levels of drug transporters along the human intestinal tract: co- 
expression of ABC and SLC transporters and comparison with Caco-2 cells. Eur J Pharm Sci. 2006;29:269-277.

44. Hilgendorf C, Ahlin G, Seithel A, Artursson P, Ungell AL, Karlsson J. Expression of thirtysix drug transporter genes in human intestine, liver, kidney, and organotypic cell lines. Drug Metab Dispos. 2007;35:1333-1340.

45. Taipalensuu J, Törnblom H, Lindberg G, Einarsson C, Sjöqvist F, Melhus H, Garberg P, Sjöström B, Lundgren B, Artursson P. Correlation of gene expression of ten drug efflux proteins of the ATP-binding cassette transporter family in normal human jejunum and in human intestinal epithelial Caco-2 cell monolayers. J Pharmacol Exp Ther. $2001 ; 299: 164-170$.

46. Sawmiller DR, Chou CC. Role of adenosine in postprandial and reactive hyperemia in canine jejunum. Am J Physiol. 1992;263:G487-G493.

47. Li N, Harris PD, Zakaria el R, Matheson PJ, Garrison RN. Microvascular responses to adenosine help explain functional and pathologic differences between intestinal segments. Am J Surg. 2004;188:526-531.

48. Strohmeier GR, Reppert SM, Lencer WI, Madara JL. The A2b adenosine receptor mediates cAMP responses to adenosine receptor agonists in human intestinal epithelia. $J$ Biol Chem. 1995;270:2387-2394.

49. Christofi FL. Purinergic receptors and gastrointestinal secretomotor function. Purinergic Signal. 2008;4:213-236.

50. Sitaraman SV, Merlin D, Wang L, Wong M, Gewirtz AT, Si-Tahar M, Madara JL. Neutrophil-epithelial crosstalk at the intestinal luminal surface mediated by reciprocal secretion of adenosine and IL-6. J Clin Invest. 2001;107:861-869.

51. Crocenzi FA, Zucchetti AE, Boaglio AC, Barosso IR, Sanchez Pozzi EJ, Mottino AD, Roma MG. Localization status of hepatocellular transporters in cholestasis. Front Biosci (Landmark Ed). 2012;17:1201-1218.

52. Dressman JB, Amidon GL, Reppas C, Shah VP. Dissolution testing as a prognostic tool for oral drug absorption: immediate release dosage forms. Pharm Res. 1998;15:11-22. 
53. Dietrich CG, Geier A, Oude Elferink RP. ABC of oral bioavailability: transporters as gatekeepers in the gut. Gut. 2003;52:1788-1795.

54. Cheeseman Cl. Upregulation of SGLT-1 transport activity in rat jejunum induced by GLP2 infusion in vivo. Am J Physiol. 1997;273:R1965-R1971.

55. Sokolovsky M, Sadeh T, Patchornik A. Nonenzymatic cleavages of peptide chains at the cysteine and serine residues through their conversion to dehydroalanine (DHAL). II. The specific chemical cleavage of cysteinyl peptides. J Am Chem Soc. 1964;86:1212-1217.

56. Legen I, Kristl A. D-glucose triggers multidrug resistance-associated protein (MRP)mediated secretion of fluorescein across rat jejunum in vitro. Pharm Res. 2004;21:635-640.

57. Arana MR, Tocchetti GN, Zecchinati F, Londero AS, Domínguez C, Perdomo V, Rigalli JP, Villanueva SSM, Mottino AD. Glucagon-like peptide 2 prevents down-regulation of intestinal multidrug resistance-associated protein 2 and P-glycoprotein in endotoxemic rats. Toxicology. 2017;390:22-31.

58. Kirkup AJ, Eastwood C, Grundy D, Chessell IP, Humphrey PP. Characterization of adenosine receptors evoking excitation of mesenteric afferents in the rat. $\mathrm{Br} J$ Pharmacol. 1998;125:1352-1360.

59. Grenz A, Zhang H, Weingart J, von Wietersheim S, Eckle T, Schnermann J, Köhle C, Kloor D, Gleiter $\mathrm{CH}$, Vallon V, Eltzschig HK, Osswald H. Lack of effect of extracellular adenosine generation and signaling on renal erythropoietin secretion during hypoxia. Am J Physiol Renal Physiol. 2007;293:F1501-F1511.

60. Asano T, Tanaka KI, Tada A, Shimamura H, Tanaka R, Maruoka H, Takenaga M, Mizushima T. Aminophylline suppresses stress-induced visceral hypersensitivity and defecation in irritable bowel syndrome. Sci Rep. 2017;7:40214.

61. Tocchetti GN, Domínguez CJ, Zecchinati F, Arana MR, Ruiz ML, Villanueva SSM, Mottino AD, Weiss J, Rigalli JP. Inhibition of multidrug resistance-associated 2 (MRP2) activity by the contraceptive nomegestrol acetate in HepG2 and Caco-2 cells. Eur J Pharm Sci. 2018;122:205-213. 
62. Hinchman CA, Matsumoto $\mathrm{H}$, Simmons TW, Ballatori N. Intrahepatic conversion of a glutathione conjugate to its mercapturic acid. Metabolism of 1-chloro-2,4-dinitrobenzene in isolated perfused rat and guinea pig livers. J Biol Chem. 1991;266:22179-22185.

63. Arana MR, Tocchetti GN, Domizi P, Arias A, Rigalli JP, Ruiz ML, Luquita MG, Banchio C, Mottino AD, Villanueva SSM. Coordinated induction of GST and MRP2 by CAMP in Caco2 cells: Role of protein kinase A signaling pathway and toxicological relevance. Toxicol Appl Pharmacol. 2015;287:178-190.

64. Zamek-Gliszczynski MJ, Xiong H, Patel NJ, Turncliff RZ, Pollack GM, Brouwer KL. Pharmacokinetics of 5 (and 6)-carboxy-2',7'-dichlorofluorescein and its diacetate promoiety in the liver. J Pharmacol Exp Ther. 2003;304:801-809.

65. Richard CL, Tan EY, Blay J. Adenosine upregulates CXCR4 and enhances the proliferative and migratory responses of human carcinoma cells to CXCL12/SDF1alpha. Int J Cancer. 2006;119:2044-2053.

66. Tan EY, Richard CL, Zhang H, Hoskin DW, Blay J. Adenosine downregulates DPPIV on HT-29 colon cancer cells by stimulating protein tyrosine phosphatase(s) and reducing ERK1/2 activity via a novel pathway. Am J Physiol Cell Physiol. 2006;291:C433-C444.

67. Huang X, Gai Y, Yang N, Lu B, Samuel CS, Thannickal VJ, Zhou Y. Relaxin regulates myofibroblast contractility and protects against lung fibrosis. Am $J$ Pathol. 2011;179:2751-2765.

68. Tocchetti GN, Domínguez CJ, Zecchinati F, Arana MR, Ruiz ML, Villanueva SSM, Weiss $\mathrm{J}$, Mottino AD, Rigalli JP. Biphasic modulation of cAMP levels by the contraceptive nomegestrol acetate. Impact on P-glycoprotein expression and activity in hepatic cells. Biochem Pharmacol. 2018;154:118-126. 


\section{Figure legends}

Fig. 1 In vivo studies: Effect of nutrients on MRP2 activity and elucidation of the extracellular mechanism involved.

a. The increase in MRP2 activity after intravenous administration of dbcAMP $(20 \mu \mathrm{mol} / \mathrm{kg}$ b.w.; $20 \mathrm{~min}$ ) validated the current model. $b$. Effect of intraluminal administration of glucose (Glc), oleic acid (OA) and glutamine (GIn) on MRP2 activity. c. Modulation of MRP2 activity after intravenous GLP-2 administration and participation of this peptide in oleic acid effect. $d$. Evaluation of the mechanism downstream GLP-2, including the mediators IGF-1 and adenosine. e. Jejunum sectioning before oleic acid treatment confirmed that the stimulus triggered by the lipid is transmitted along the intestinal wall. Data are presented as $\%$ of the corresponding control group and expressed as mean \pm standard deviation $(n=4){ }^{*}: p<0.05$

Fig. 2 In vivo studies: Oleic acid acutely increases apical MRP2 localization by a GLP-2-mediated mechanism.

MRP2 was labeled with Alexa Fluor 555 (red fluorescence) and nuclei were stained with the blue dye Hoechst 33258 (images from the top row). For the sake of clarity, grayscale images are included showing only the MRP2 channel. Fluorescence intensity distribution along a $30 \mu \mathrm{m}$ line parallel to the longitudinal axis of the enterocyte (distance represented in x-axis) was evaluated for red and blue channels ( $n=20$ per group). To detect changes in the distribution of MRP2 curve, all data sets were scaled to the same arbitrary area under the curve value and the resulting curves were aligned using the nuclei channel as a reference. Additionally, MRP2 peak height was calculated, expressed as mean \pm standard deviation and compared between groups. * $p<0.05$ versus the two remaining groups. White scale bar represents $10 \mu \mathrm{m}$

Fig. 3 Studies in Caco-2 cells: Adenosine acutely increases MRP2 activity through A2BAR and PKA activation.

a. Permeability coefficients (Papp) of the MRP2 substrate CDF after $120 \mathrm{~min}$, in both apical to basolateral $(A B)$ and basolateral to apical (BA) directions. $b$. The CDF efflux ratio represents the quotient between both permeabilities and properly estimates MRP2 
activity. MRS: $10 \mu \mathrm{M}$ MRS 1754. KT: $1 \mu \mathrm{M}$ KT5720. Data are expressed as mean \pm standard deviation $(n=4) .{ }^{*}: p<0.05$

Fig. 4 Studies in Caco-2 cells: Adenosine acutely increases apical MRP2 localization through A2BAR activation.

Main images represent the top view of the cell monolayer. Images created by stacking along the $Z$ axis are shown on the right and at the bottom. A small region of the $Z$-axis images from each group is shown with higher magnification as an inset. MRP2 was labeled with red fluorescence whereas the nuclei, in blue, were stained with Hoechst 33258. Fluorescence intensity distribution along a $10 \mu \mathrm{m}$ line parallel to the longitudinal axis of the cells (distance represented in X-axis) was evaluated for red and blue channels ( $n=20$ per group). To detect changes in the distribution of MRP2 among groups, all data sets were scaled to the same arbitrary area under the curve value and the resulting curves were aligned using the nuclei channel as a reference. Additionally, MRP2 peak height was calculated, expressed as mean \pm standard deviation and compared between groups. * $p<0.05$ versus the two remaining groups. White scale bar represents $10 \mu \mathrm{m}$

Fig. 5 Sequence of events in the regulation of MRP2 by oleic acid.

Taken together, the data allow us to propose the following sequence of events. After ingestion, intraluminal oleic acid stimulates intestinal $L$ cells to release GLP-2 towards the basolateral pole (1). GLP-2 in turn binds to its receptor in enteric neurons (2) which, either by themselves or through activation of other cell types, release one or more of the possible adenosine precursors (3). CD73 catalyzes the hydrolysis of extracellular AMP to adenosine (4), a nucleoside able to increase MRP2 apical localization and activity in the enterocyte via the A2BAR/cAMP/PKA axis (5)

\section{Fig. 6 In vivo model for assessment MRP2 activity and localization.}

a. Studies were performed in two well identified and separated regions based on the highest MRP2 expression (proximal jejunum) and the highest presence of GLP-2 producing $L$ cells (distal jejunum and ileum). b. For direct stimulation of $L$ cells, nutrients were intraluminally incorporated into distal jejunum (left panel). In contrast, and due to their action from the serosal side of the epithelium, dbcAMP, GLP-2 and adenosine were 
systemically administered into the femoral vein (right panel). After 20 min of treatment, MRP2 activity was determined. c. Pretreatments to assess mechanistical aspects underlying oleic acid effect consisted of both the immunoneutralization of GLP-2 or IGF-1 and the inhibition of CD73 or A2BAR by intraperitoneal injection of antibodies or selective inhibitors, respectively (left panel). To assess whether the signal triggered by oleic acid is transmitted along the intestinal wall, the jejunum was sectioned to physically separate the two regions referred above (right panel). All these procedures were followed by oleic acid intraluminal treatment. $d$. After treatments, DNP-SG efflux was determined to estimate MRP2 activity. For that purpose, a $15 \mathrm{~cm}$ intestinal sac was created right after the ligament of Treitz (proximal jejunum) and filled with a solution of the parent compound CDNB. After $30 \mathrm{~min}$, the amount of DNP-SG secreted to the luminal compartment was quantified by HPLC-UV

\section{Fig. 7 MRP2 localization studies: densitometric data collection.}

All procedures were performed using ImageJ software on images obtained by confocal microscopy. a. Distribution of fluorescence intensity was evaluated along a $30 \mu \mathrm{m}$ line parallel to the longitudinal axis of the enterocyte. $b$. Next, the channels corresponding to the nuclei (graph on the left) and MRP2 (graph on the right) were separated and plotted. This procedure was repeated until obtaining 20 pairs of graphs for each experimental group 

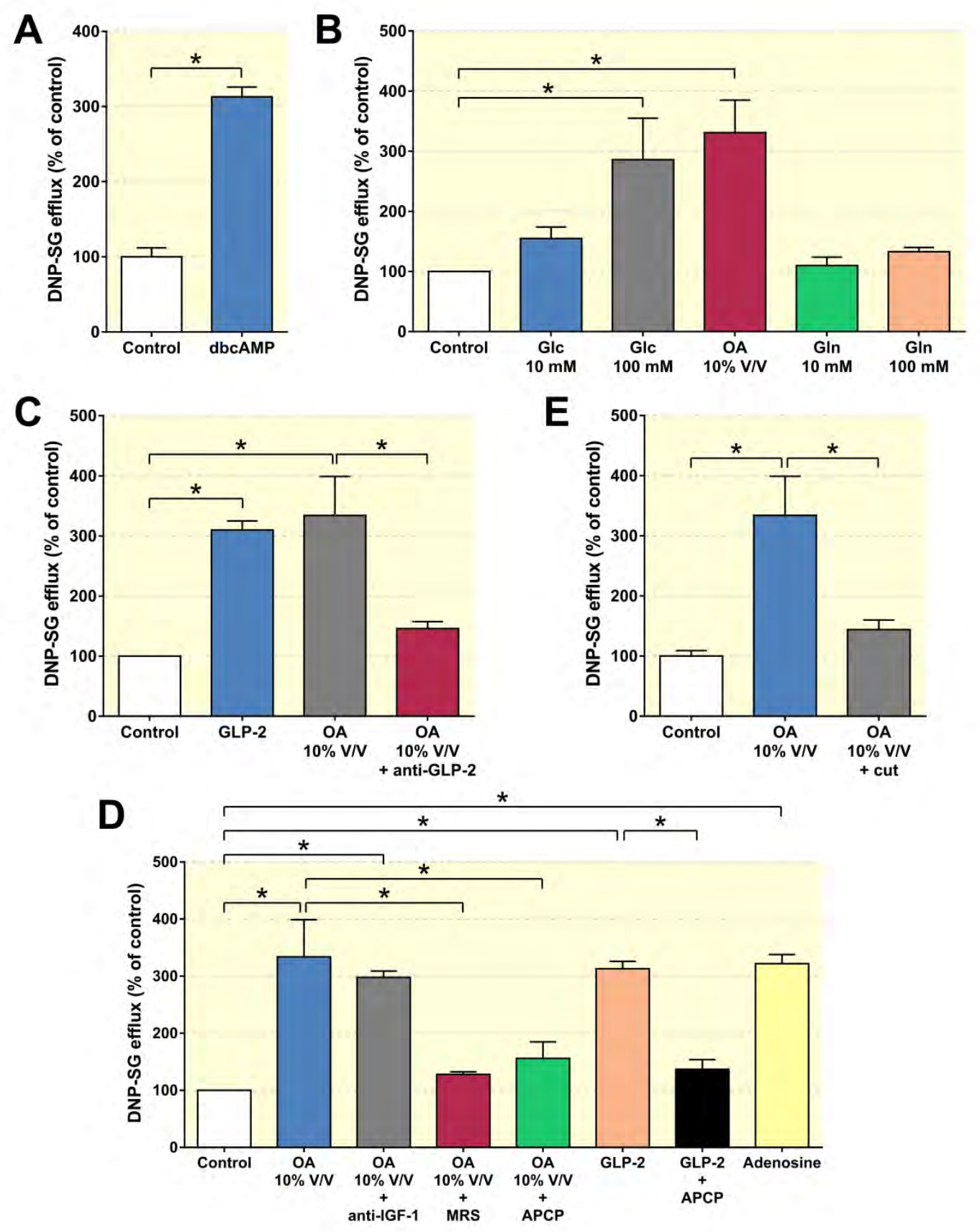

apha_13514_f1.jpg 

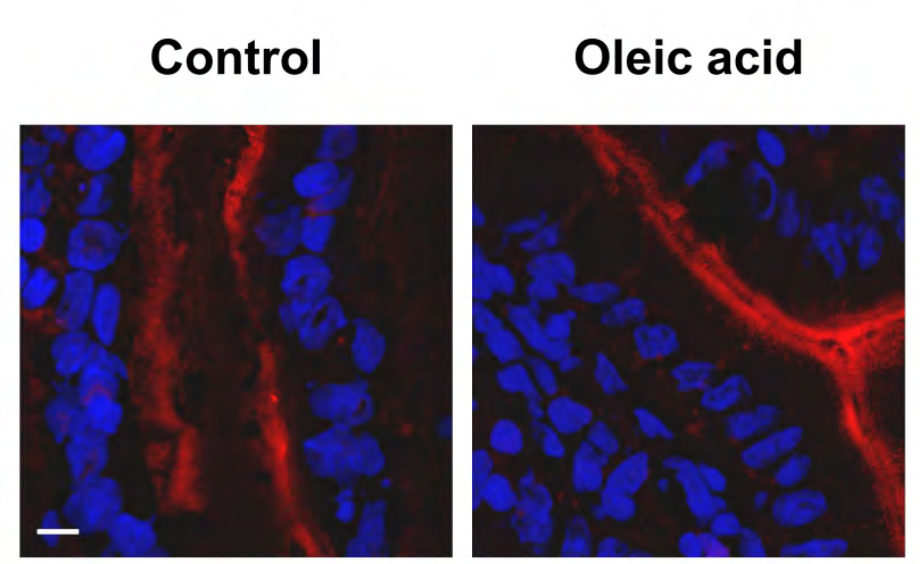

\section{Oleic acid + anti-GLP-2}
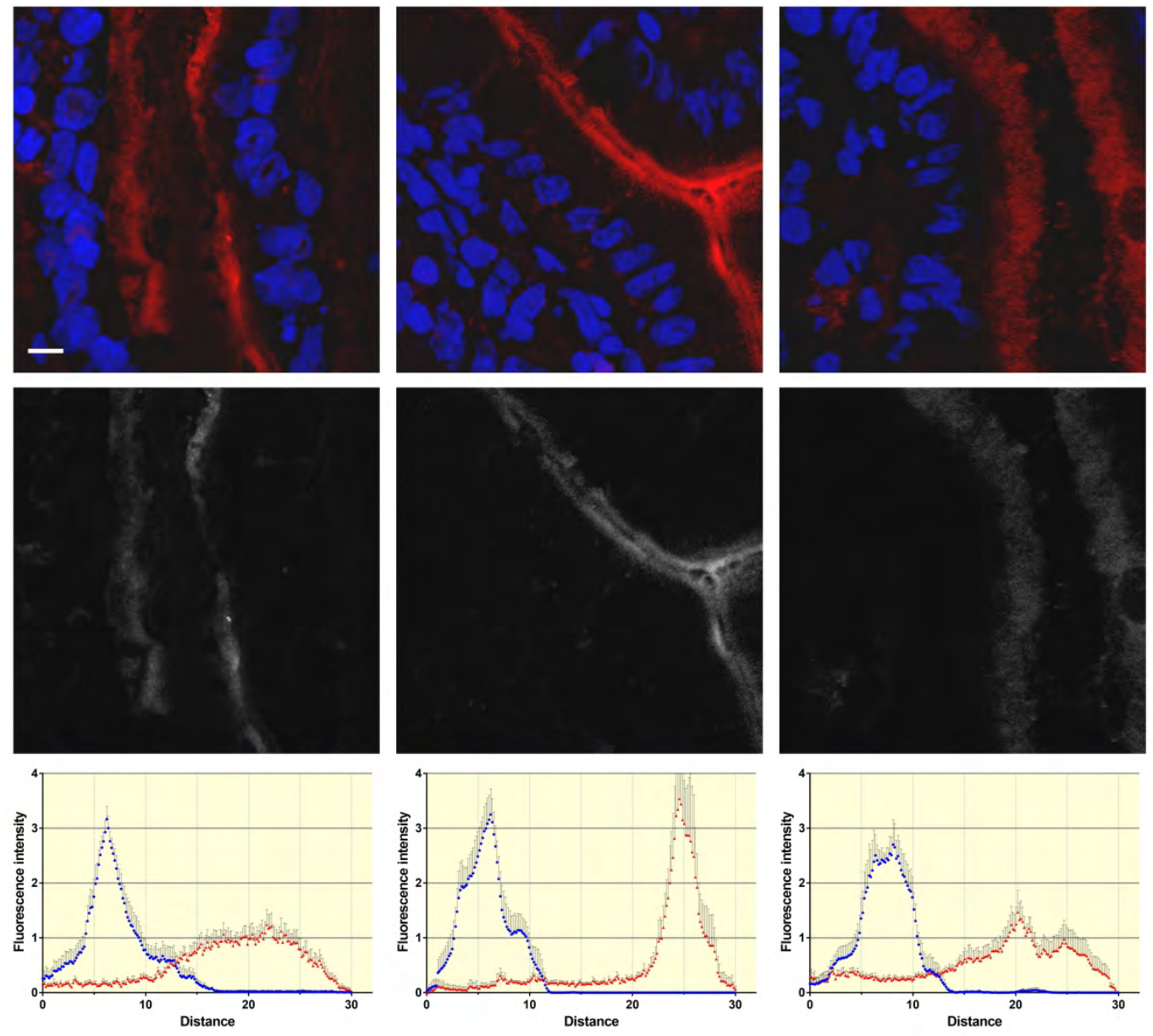

MRP2 peak height: $1.24 \pm 0.26$

MRP2 peak height: $3.53 \pm 1.19^{*}$

apha_13514_f2.jpg

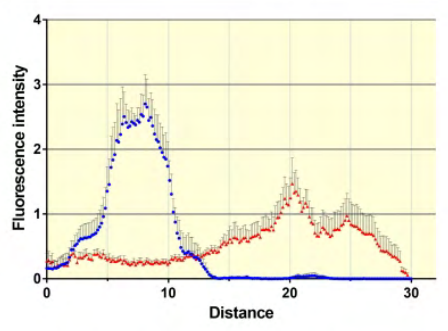

MRP2 peak height: $1.47 \pm 0.35$ 

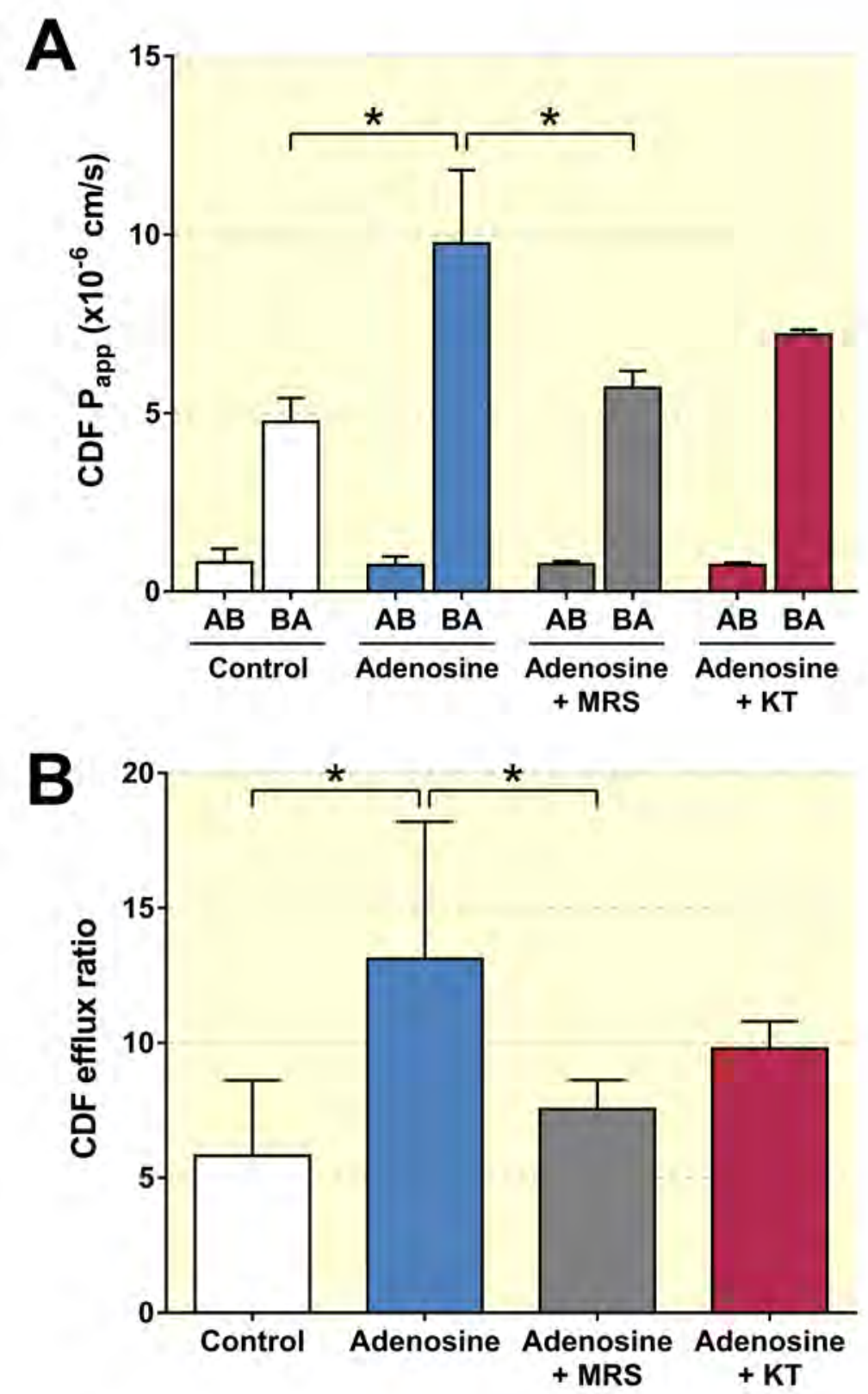

apha_13514_f3.jpg 
Control
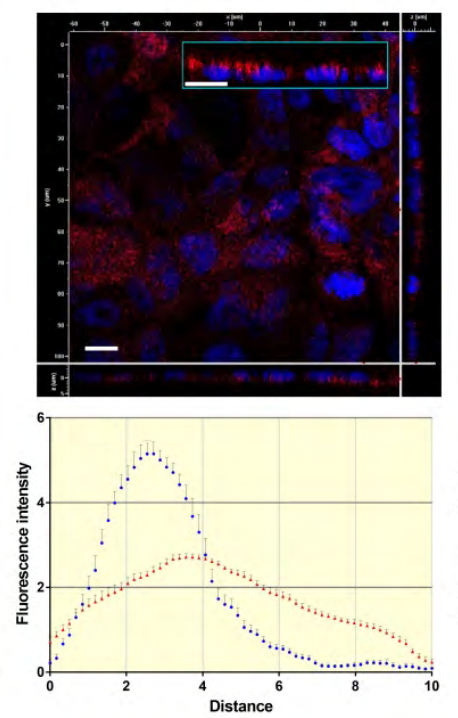

MRP2 peak height:

$2.71 \pm 0.08$
Adenosine
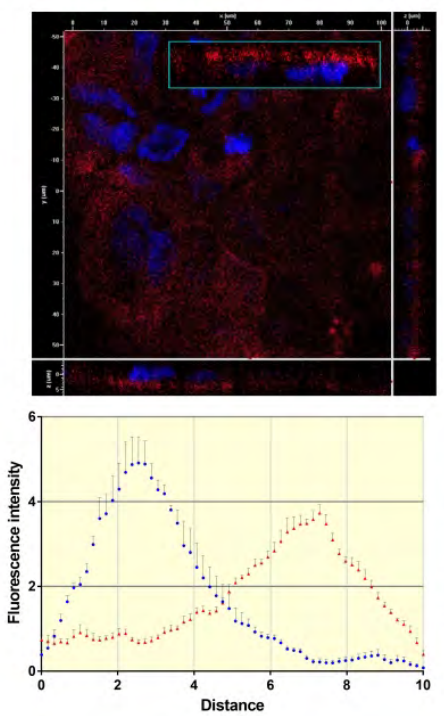

MRP2 peak height: $3.73 \pm 0.20^{*}$

apha_13514_f4.jpg
Adenosine + MRS 1754
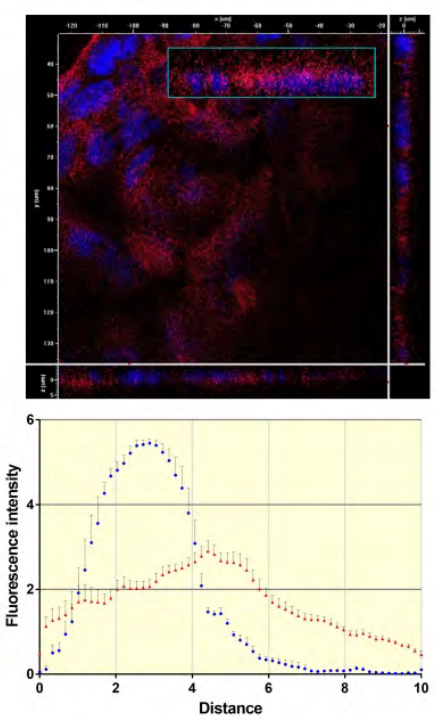

MRP2 peak height: $2.90 \pm 0.25$ 


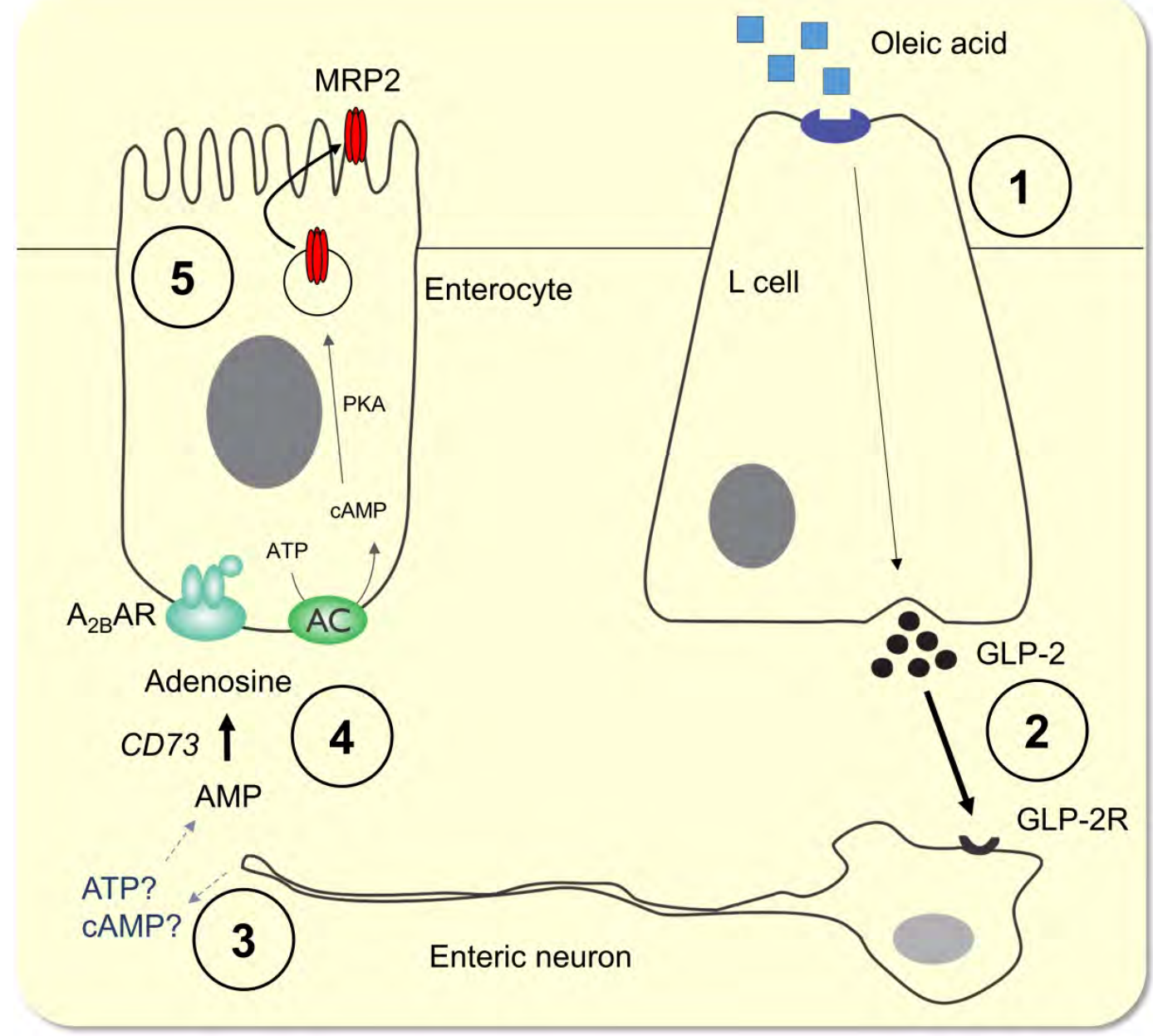

apha_13514_f5.jpg

This article is protected by copyright. All rights reserved 


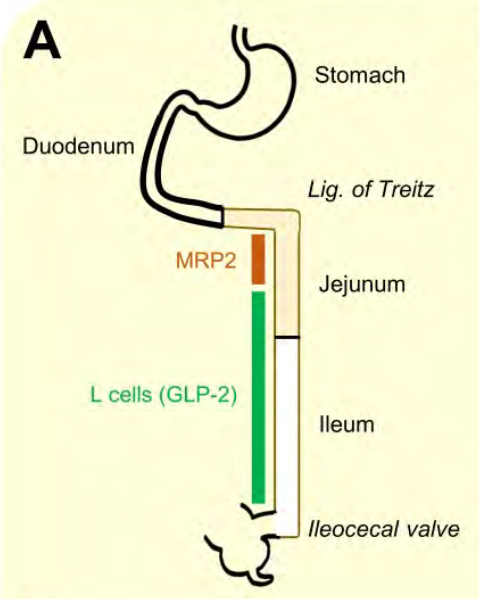

\section{C}

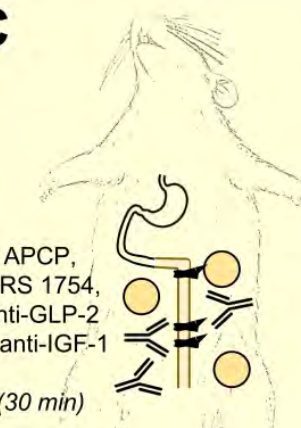

B

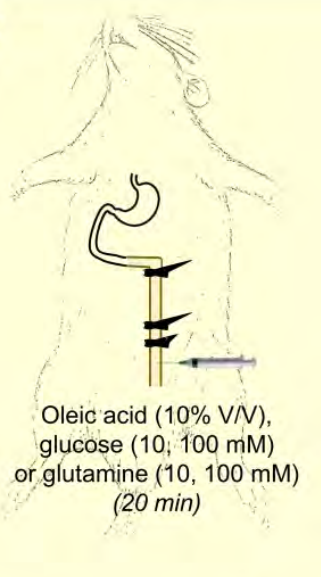

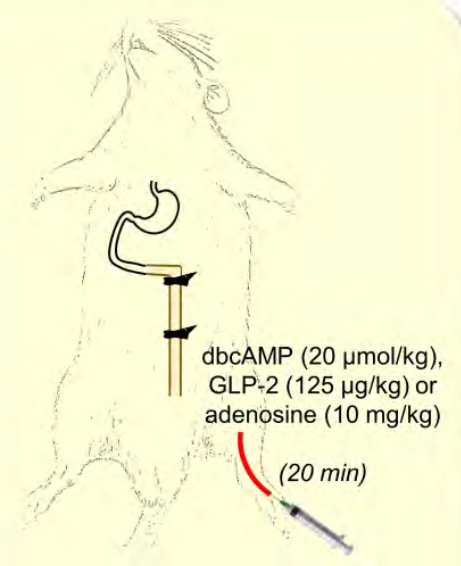

D

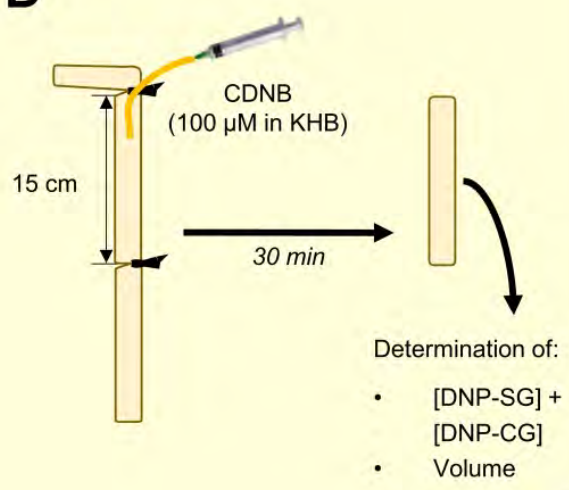

apha_13514_f6.jpg 


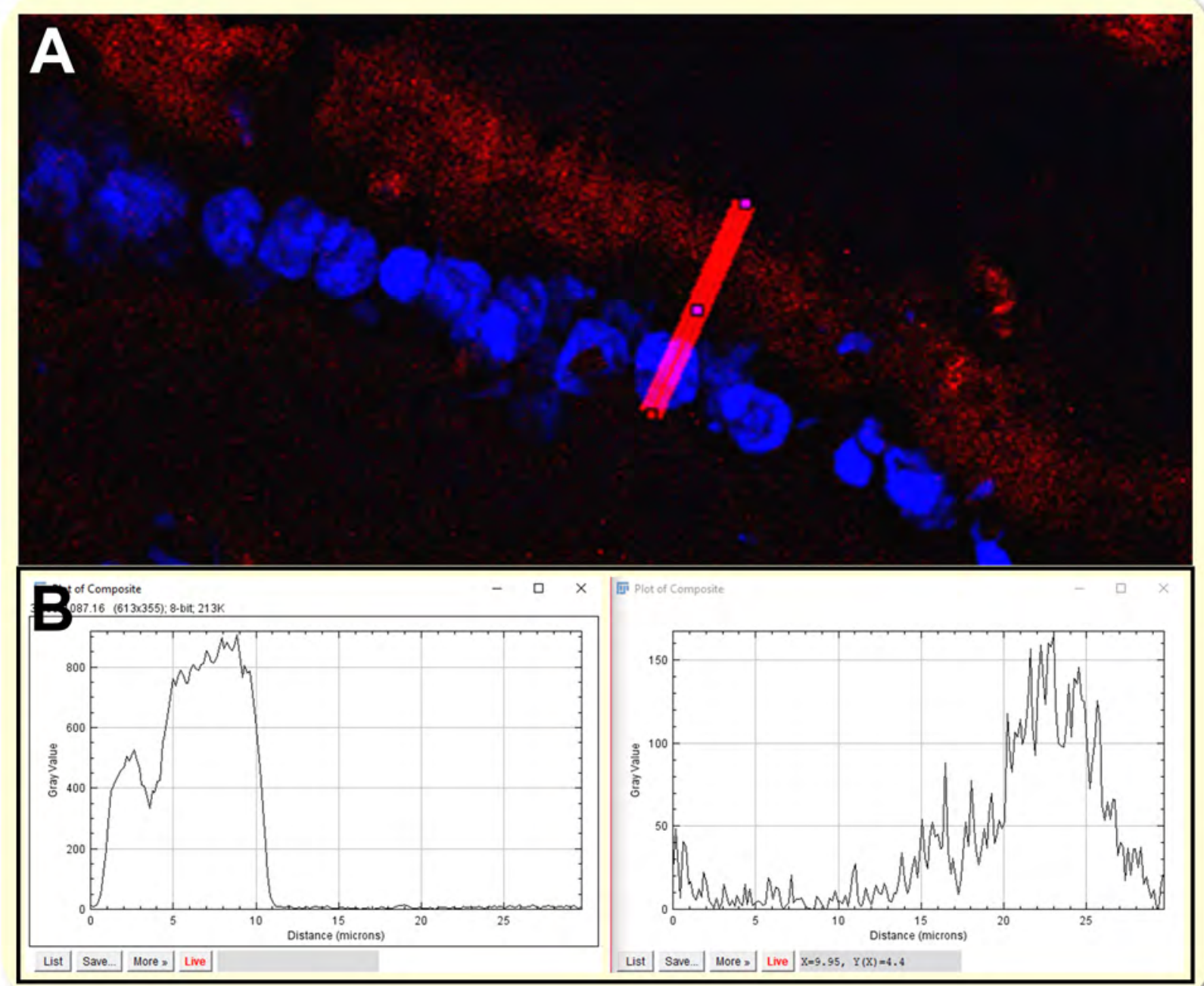

apha_13514_f7.jpg 